\title{
MicroRNA-1291-5p Sensitizes Pancreatic Carcinoma Cells to Arginine Deprivation and Chemotherapy through the Regulation of Arginolysis and Glycolysis
}

\author{
Mei-Juan Tu, Zhijian Duan, Zhenzhen Liu, Chao Zhang, Richard J. Bold, Frank J. Gonzalez, \\ Edward J. Kim, and (D)Ai-Ming Yu \\ Department of Biochemistry and Molecular Medicine (M.-J.T., Z.D., Z.L., C.Z., A.-M.Y.), Division of Surgical Oncology (R.J.B.), \\ Division of Hematology and Oncology, Department of Internal Medicine (E.J.K.), University of California (UC) Davis School of \\ Medicine, Sacramento, California; and Laboratory of Metabolism, National Cancer Institute, National Institutes of Health, \\ Bethesda, Maryland (F.J.G.)
}

Received July 24, 2020; accepted September 17, 2020

\begin{abstract}
Cancer cells are dysregulated and addicted to continuous supply and metabolism of nutritional glucose and amino acids (e.g., arginine) to drive the synthesis of critical macromolecules for uncontrolled growth. Recent studies have revealed that genome-derived microRNA (miRNA or miR)-1291-5p (miR1291-5p or miR-1291) may modulate the expression of argininosuccinate synthase (ASS1) and glucose transporter protein type 1 (GLUT1). We also developed a novel approach to produce recombinant miR-1291 agents for research, which are distinguished from conventional chemo-engineered miRNA mimics. Herein, we firstly demonstrated that bioengineered miR-1291 agent was selectively processed to high levels of target miR1291-5p in human pancreatic cancer (PC) cells. After the suppression of ASS1 protein levels, miR-1291 perturbed arginine homeostasis and preferably sensitized ASS1-abundant L3.3 cells to arginine deprivation therapy. In addition, miR1291 treatment reduced the protein levels of GLUT1 in both AsPC-1 and PANC-1 cells, leading to a lower glucose uptake (deceased $>40 \%$ ) and glycolysis capacity (reduced approximately 50\%). As a result, miR-1291 largely improved cisplatin
\end{abstract}

efficacy in the inhibition of $\mathrm{PC}$ cell viability. Our results demonstrated that miR-1291 was effective to sensitize PC cells to arginine deprivation treatment and chemotherapy through targeting ASS1- and GLUT1-mediated arginolysis and glycolysis, respectively, which may provide insights into understanding miRNA signaling underlying cancer cell metabolism and development of new strategies for the treatment of lethal PC.

\section{SIGNIFICANCE STATEMENT}

Many anticancer drugs in clinical use and under investigation exert pharmacological effects or improve efficacy of coadministered medications by targeting cancer cell metabolism. Using new recombinant miR-1291 agent, we revealed that miR-1291 acts as a metabolism modulator in pancreatic carcinoma cells through the regulation of argininosuccinate synthase- and glucose transporter protein type 1-mediated arginolysis and glycolysis. Consequently, miR-1291 effectively enhanced the efficacy of arginine deprivation (pegylated arginine deiminase) and chemotherapy (cisplatin), offering new insights into development of rational combination therapies.

\section{Introduction}

Metabolism reprogramming is one of the major hallmarks of cancer cells, with higher rates of nutrients (e.g., glucose and

This study was supported by the funding from National Cancer Institute [Grant R01-CA225958] and National Institute of General Medical Sciences [Grant R01-GM113888] as well as the University of California (UC) Davis Clinical and Translational Science Center (CTSC) Pilot Translational and Clinical Studies Program funded by the National Center for Advancing Translational Sciences [Grant UL1-TR001860], National Institutes of Health The authors also appreciate the access to the Molecular Pharmacology Shared Resources funded by the UC Davis Comprehensive Cancer Center Support Grant (CCSG) awarded by the National Cancer Institute [Grant P30CA093373].

https://doi.org/10.1124/molpharm.120.000130. amino acids) transport and metabolism than normal cells essential for rapid proliferation (DeBerardinis and Chandel, 2016; Counihan et al., 2018). Cells predominately metabolize glucose through glycolysis in cytoplasm and oxidative phosphorylation in mitochondria to produce ATP (Pavlova and Thompson, 2016; Martinez-Outschoorn et al., 2017). Different from normal cells, many carcinoma cells prefer the utilization of glycolysis-derived ATP rather than oxidative phosphorylation-produced ATP, which is called "Warburg effect" or aerobic glycolysis (Hsu and Sabatini, 2008; Asgari et al., 2015). To meet a high demand of glucose, glucose transporter protein type 1 (GLUT1) is commonly upregulated

ABBREVIATIONS: AA, antimycin A; ACN, acetonitrile; ASS1, argininosuccinate synthase; CI, confidence interval; ECAR, extracellular acidification rate; FA, formic acid; GLUT1, glucose transporter protein type 1; IS, internal standard; KRB, Krebs-Ringer bicarbonate; LC-MS/MS, liquid chromatography tandem mass spectroscopy; miRNA or miR, microRNA; MSA, Sephadex aptamer-tagged methionyl-transfer RNA; 2-NBDG, 2-(N-(7-nitrobenz-2-oxa-1,3-diazol-4-yl) amino)-2 deoxyglucose; OCR, oxygen consumption rate; PC, pancreatic cancer; PCR, polymerase chain reaction; PEG-ADI, pegylated arginine deiminase; PER, proton efflux rate; pre-miR-1291, miR-1291 precursor; ROT, rotenone; RT-qPCR, reversetranscription quantitative real-time PCR. 
in various cancer types (Ooi and Gomperts, 2015). As such, there are growing interests in developing new strategies to target glycolysis for the treatment of cancers or to improve the efficacy of existing therapies (Counihan et al., 2018; Dai et al., 2020; Xi et al., 2020).

Aberrant aminolyses are well recognized in cancer cells (Pavlova and Thompson, 2016; Martinez-Outschoorn et al., 2017), whereas amino acids are vital components for protein synthesis and signaling transduction (Wu, 2013). Arginine is a semiessential amino acid that can be synthesized within cells from citrulline via argininosuccinate lyase and the ratelimiting enzyme argininosuccinate synthase (ASS1) but not necessarily at sufficient quantities and therefore may need to be supplemented by extracellular stores generated by diet. Synthesis of arginine within cells is often downregulated in many kinds of cancers, including pancreatic cancer (PC), and thus these cancer cells become more dependent on the extracellular stores of arginine from the diet (Delage et al., 2010). Therefore, arginine deprivation therapy has emerged as a new strategy to combat tumor cells that are auxotrophic for arginine because of ASS1 downregulation (Delage et al., 2010; Patil et al., 2016). Arginine deprivation can be achieved by using pegylated arginine deiminase (PEG-ADI), which catalyzes arginine back to citrulline. Our previous studies have revealed that PC cells showing high levels of ASS1 with high levels of intracellular arginine are resistant to PEG-ADI because they do not rely on extracellular arginine (Bowles et al., 2008; Daylami et al., 2014). This observation led us to hypothesize that downregulation of ASS1 may improve the susceptibility of PC cells to PEG-ADI.

$\mathrm{PC}$ is the fourth leading cause of cancer-related death in the United States, with a relatively low 5-year survival rate $(9 \%)$ (Siegel et al., 2020). Advances in the diagnosis, therapies, and prognosis of PC are still limited, and thus more efficient therapeutic strategies to combat this lethal disease are urgently needed. With the discovery of functional noncoding microRNAs (miRNAs or miRs) in the regulation of cancer cellular processes (Ha and Kim, 2014; Gebert and MacRae, 2019), some miRNAs (e.g., miR-34 and miR-124) have been revealed to directly target critical factors underlying PC cell metabolism (Nalls et al., 2011; Wu et al., 2018). Our recent studies revealed that miR-1291-5p (or miR-1291) is downregulated in patient with $\mathrm{PC}$ specimens when compared with adjacent normal tissues (Tu et al., 2016). We also found miR1291 acts as a tumor suppressor in PC cells through the modulation of cell metabolome and induction of apoptosis and cell cycle arrest (Bi et al., 2014; Tu et al., 2016). Further study of proteomics showed that ASS1 was one of the most downregulated proteins in miR-1291-expressing PC cells (Tu et al., 2016), although ASS1 is not a direct target of miR-1291. In addition, it was reported that miR-1291 suppresses renal carcinoma cell viability via direct targeting of GLUT1 (Yamasaki et al., 2013), supporting the oncolytic role of miR1291.

To assess miRNA functions and therapeutic potential, we have established a novel, in vivo fermentation-based approach to achieve high-yield and large-scale production of recombinant or bioengineered miRNA agents (Chen et al., 2015; Wang et al., 2015; Ho et al., 2018). In particular, human miR-1291 precursor (pre-miR-1291) is fused to a Sephadex aptamer-tagged methionyl-transfer RNA (MSA) scaffold, namely MSA/miR-1291, to achieve overexpression in Escherichia coli, and recombinant miR-1291 agent is further purified to a high degree of homogeneity (e.g., > 97\%) for functional studies ( $\mathrm{Li}$ et al., 2015; Tu et al., 2019). Our very recent study has also demonstrated that bioengineered miR1291 "prodrug" alone or in combination with gemcitabine and paclitaxel is effective to suppress tumor growth in PC xenograft mouse models (Tu et al., 2019).

This study was to investigate the effectiveness of miR-1291 in the regulation of GLUT1 and ASS1 and consequent impact of PC cell metabolism as well as sensitization to arginine deprivation and chemotherapy. Our data showed that MSA/ miR-1291 was selectively processed to target miR-1291-5p in human PC cells. Through a preferable reduction of ASS1 protein levels in ASS1-abundant L3.3 cells, miR-1291 markedly decreased intracellular arginine levels and largely improved cell sensitivity to PEG-ADI therapy. In addition, miR1291 reduced GLUT1 expression to alter glucose uptake, leading to the inhibition of glycolysis and sensitization of PC cells to chemotherapeutic drug cisplatin.

\section{Material and Methods}

Materials. 2-( $N$-(7-nitrobenz-2-oxa-1,3-diazol-4-yl) amino)-2 deoxyglucose (2-NBDG), Lipofectamine 3000, radioimmunoprecipitation assay buffer, and BCA protein assay kit were purchased from Thermo Fisher Scientific (Waltham, MA). CellTiter-Glo 2.0 assay was obtained from Promega (Madison, WI). Phenol, ethanol, cisplatin, protease inhibitor cocktail, Trizol reagent, and anti- $\beta$-actin antibody (A5441) were purchased from Sigma-Aldrich (St. Louis, MO). Anti-ASS1 antibody (66036-1-Ig) was purchased from Proteintech (Rosemont, IL). Anti-GLUT1 antibody (ab32551) was obtained from Abcam (Cambridge, MA). Polyvinylidene difluoride membrane, blottinggrade blocker, and Western ECL substrate kit were purchased from Bio-Rad (Hercules, CA). Direct-zol RNA MiniPrep kit was bought from Zymo Research (Irvine, CA). PEG-ADI was generously provided by DesigneRx Pharmacologics (Vacaville, CA) (Bowles et al., 2008). All other chemicals and organic solvents of analytical grade were purchased from Thermo Fisher Scientific or Sigma-Aldrich.

Cell Culture and Transfection. Human PC AsPC-1, PANC-1, and L3.3 cells were purchased from the American Type Culture Collection (Manassas, VA) and cultured in RPMI 1640 or Dulbecco's modified Eagle's medium supplemented with $10 \%$ fetal bovine serum at $37^{\circ} \mathrm{C}$ in a humidified incubator with $5 \% \mathrm{CO}_{2}$. Cells were seeded in cell culture plates and incubated overnight and then transfected with biologic RNAs by using LipofectAMINE 3000 reagent (Life Technologies, Grand Island, NY).

Expression and Purification of Recombinant RNA Agents. Production of recombinant MSA/miR-1291 or control MSA was conducted as described ( $\mathrm{Li}$ et al., 2015; Wang et al., 2015; Ho et al., 2018). Briefly, RNA expression plasmids were transformed into HST08 E. coli and incubated in ampicillin-containing $(100 \mu \mathrm{g} / \mathrm{ml})$ $\mathrm{LB}$ medium at $37^{\circ} \mathrm{C}$ overnight. Total bacterial RNAs were extracted using Tris- $\mathrm{HCl}$ saturated phenol method and then were analyzed by denaturing urea polyacrylamide gel electrophoresis (PAGE) analysis to verify the expression of recombinant RNAs. Purification of MSA/ miR-1291 from total RNA was conducted on an NGC QUEST 10 PLUS fast protein liquid chromatography system (Bio-Rad) consisting of a fraction collector by using an anion exchange Enrich-Q $10 \times 100$ column (Bio-Rad). Fractions containing pure MSA/miR-1291 or MSA, which were validated by denaturing urea PAGE, were pooled and precipitated by ethanol and then desalted and concentrated by Amicon ultra-2 ml centrifugal filters (30 kDa; EMD Millipore, Billerica, MA). Purity of isolated RNA was quantitatively determined by a highperformance liquid chromatography method (Wang et al., 2015). RNAs showing high level of homogeneity ( $>97 \%$ ) were used in this study. 
Reverse-Transcription Quantitative Real-Time Polymerase Chain Reaction. Cells treated with MSA or MSA/miR-1291 (5 nM in PANC-1 and L3.3 cells, $2 \mathrm{nM}$ in AsPC-1 cells) were harvested at 48 or 72 hours post-transfection. Total RNAs were extracted with Direct-zol RNA MiniPrep kit (Zymo Research) and reverse-transcribed using NxGen M-MuLV reverse transcriptase (Lucigen, Middleton, WI) supplemented with random hexamer primer (Thermo Fisher Scientific) for pre-miR-1291 and U6 or TaqMan small RNA assay kit for mature miR-1291 (Thermo Fisher Scientific). Reverse-transcription quantitative real-time PCR (RT-qPCR) was conducted on a CFX96 Touch real-time PCR system (Bio-Rad) by using specific primers for pre-miR-1291 (Forward 5'-GGT AGA ATT CCA GTG GCC CTG ACT GA-3', Reverse 5'-CAG GAA GAC AGT CCT TTA GGC CTC TG-3') and U6 (Forward 5'-CTC GCT TCG GCA GCA CA-3', Reverse 5'-AAC GCT TCA CGA ATT TGC GT-3') and TaqMan small RNA assay kit for mature miR-1291. The relative expression of target gene was calculated with Eq. $2^{-\Delta \Delta \mathrm{Ct}}$, in which $\Delta \mathrm{Ct}$ was the difference of cycle number (Ct) value between target gene and internal standard, U6.

Western Blot. Human PC cells were transfected with MSA or MSA/miR-1291 (5 nM in AsPC-1 cells, $10 \mathrm{nM}$ in L3.3 cells, and $20 \mathrm{nM}$ in PANC-1 cells) for 48 or 72 hours and then lysed with radioimmunoprecipitation assay buffer supplemented with proteinase inhibitors cocktail (Sigma). Protein concentration of the cell lysates were determined by BCA assay. Whole cell proteins (30-40 $\mu \mathrm{g} / \mathrm{lane})$ were separated in 10\% SDS-PAGE gels and then electrophoretically transferred onto polyvinylidene difluoride membranes. After being incubated with 5\% blotting-grade blocker, the membranes were incubated with primary anti-ASS1 (1:1000), anti-GLUT1 (1:1000), or anti- $\beta$-actin (1:5000) antibody. The membranes were then incubated with secondary peroxidase goat anti-rabbit or mouse IgG followed by ECL substrates incubation, and the blots were obtained by using ChemiDoc MP Imaging System (Bio-Rad).

Glucose Uptake Assay. AsPC-1 or PANC-1 cells were plated in 96-well plates and treated with MSA or MSA/miR-1291 (5 nM in AsPC-1 cells and $20 \mathrm{nM}$ in PANC-1 cells) for 48 hours. Cells were washed twice with $37^{\circ} \mathrm{C}$ glucose-free Krebs Ringer bicarbonate (KRB) buffer (110 mM NaCl, $4.4 \mathrm{mM} \mathrm{KCl,} 1.45 \mathrm{mM} \mathrm{KH}_{2} \mathrm{PO} 4,1.2 \mathrm{mM} \mathrm{MgCl}_{2}$, $2.3 \mathrm{mM} \mathrm{CaCl}_{2}, 4.8 \mathrm{mM} \mathrm{NaHCO}_{3}, 10 \mathrm{mM}$ HEPES), preincubated with $\mathrm{KRB}$ buffer in a $5 \% \mathrm{CO}_{2}$ incubator at $37^{\circ} \mathrm{C}$ for 15 minutes, and then incubated with KRB buffer containing $600 \mu \mathrm{M}$ 2-NBDG for 1 to 2 hours. After removing the incubation buffer, cells were washed with ice-cold PBS three times, and then another $100 \mu \mathrm{l}$ of PBS was added to each well to immediately measure the fluorescence intensity by excitation at $465 \mathrm{~nm}$ and emission at $540 \mathrm{~nm}$ (Kawauchi et al., 2008; Yamamoto et al., 2011). At the end of the assay, cells were lysed with $0.2 \%$ SDS, and the protein concentration was determined by BCA assay. Fluorescence was normalized to protein concentration of each sample, and vehicle control group was set as $100 \%$ for comparison.

Liquid Chromatography Tandem Mass Spectroscopy. Levels of arginine, glucose, and lactate were determined by using an $\mathrm{AB}$ Sciex 4000 QTRAP tandem mass spectrometry system (AB Sciex, Framingham, MA) equipped with a Shimadzu Prominence Ultra-Fast Liquid Chromatography system (Shimadzu Corporation, Kyoto, Japan). All the samples were separated on an Intrada Amino Acid column $(3 \times$ $50 \mathrm{~mm}, 3 \mu \mathrm{m}$; ImtaktUSA, Portland, OR). Data were analyzed and quantified by the Analyst software (Version 1.6.2; AB Sciex).

Cells were seeded in six-well plates and treated with MSA or MSA/ miR-1291 (5 nM in AsPC-1 cells, $10 \mathrm{nM}$ in L3.3 cells, and $20 \mathrm{nM}$ in PANC-1 cells) for 48 hours. Cell culture medium was collected at the end of the incubation, and the cells were scraped off the plates after three quick washes with ice-cold PBS and then transferred to $1.5-\mathrm{ml}$ tubes. The cells were washed one more time by centrifugation at $3000 \mathrm{~g}$ for 5 minutes at $4^{\circ} \mathrm{C}$, resuspended with water, and then lysed by three freeze-thaw cycles (freeze the cells with liquid nitrogen and thaw the cells by sonication for 2 minutes in a water bath sonicator). Cell lysates were centrifuged at $13,000 \mathrm{~g}$ for 10 minutes at $4^{\circ} \mathrm{C}$ to remove the undissolved cell debris. After the determination of protein concentration by BCA assay, the supernatants were stored at $-80^{\circ}$
C until liquid chromatography tandem mass spectroscopy (LC-MS/ MS) analysis.

Arginine level was determined as recently reported (Liu et al., 2019; Yi et al., 2020) with minor modification. Briefly, $200 \mu$ l cell lysates (200 ng protein/ $\mu \mathrm{l}$ ) was added to $800 \mu \mathrm{l}$ of internal standard (IS) (4-chloro-phenylalanine, $0.05 \mu \mathrm{M}$ )-containing acetonitrile $(\mathrm{ACN})$ to precipitate the protein, vortexed for 5 minutes, and then centrifuged at $16,000 \mathrm{~g}$ for 15 minutes. The supernatants were transferred to new vials and dried over air at room temperature. The resultant residues were redissolved with $200 \mu \mathrm{l}$ ACN-water $\left(\mathrm{ACN}: \mathrm{H}_{2} \mathrm{O}=4: 1, v / v\right)$ containing $1 \%$ formic acid (FA) and vigorously mixed. After centrifugation at $16,000 \mathrm{~g}$ for 15 minutes, the supernatants were transferred to new vials and injected for LC-MS/MS detection. Samples were separated by a gradient elution with the mobile phases comprised of solution $\mathrm{A}(100 \mathrm{mM}$ ammonium formate) and solution B (5\% water $+95 \% \mathrm{ACN}+$ $0.3 \% \mathrm{FA})$ at a flow rate of $0.6 \mathrm{ml} / \mathrm{min}$. The compounds were detected in positive electrospray ionization mode with multiple reaction monitoring, $\mathrm{m} / \mathrm{z} 175.1 \rightarrow 70.1$ for arginine and $\mathrm{m} / \mathrm{z} 200.1 \rightarrow 154.1$ for the IS.

To measure glucose and lactate levels, cell culture medium was diluted to 5000 folds with water. Cell lysates were diluted with water to achieve the same protein concentration $(200-300 \mathrm{ng} / \mu \mathrm{l})$ for each sample. One volume of the diluted medium or cell lysates was added into three volumes of ACN containing $0.4 \% \mathrm{FA}$ and IS (5-fluorouracil, final concentration $0.5 \mu \mathrm{M}$ ) to precipitate the proteins. The samples were vortexed for 2 minutes and centrifuged at $16,000 \mathrm{~g}$ for 15 minutes. Supernatant was transferred to a new vial and injected for LC-MS/MS analysis as we reported recently (Yi et al., 2020). Multiple reaction monitoring at negative electrospray ionization mode was used to monitor the target compounds, specifically $178.9 \rightarrow 88.9$ for glucose, $88.8 \rightarrow 43$ for lactate, and $129 \rightarrow 42$ for the IS.

Glycolytic Rate Assay. AsPC-1 and PANC-1 cells were seeded in the XFe24 microplates and transfected with MSA or MSA/miR-1291 ( $5 \mathrm{nM}$ for AsPC-1 cells and $20 \mathrm{nM}$ for PANC-1 cells). Forty-eight hours later, cell glycolytic profile was evaluated using an Agilent Seahorse XF Glycolytic Rate Assay Kit (Agilent, Santa Clara, CA) by measuring the real-time oxygen consumption rate (OCR) and extracellular acidification rate (ECAR) on a Seahorse XFe24 Flux Analyzer (Agilent) according to the manufacturer's instructions. Briefly, cells were incubated with XF medium in the absence of metabolic inhibitors to record the basal OCR and ECAR levels and then rotenone (ROT) $(0.5 \mu \mathrm{M})$ plus antimycin A (AA) $(0.5 \mu \mathrm{M})$ and 2-deoxy-D-glucose $(50 \mathrm{mM})$ were serially injected to determine basal glycolysis and compensatory glycolysis levels. Data were normalized to protein concentrations of corresponding cell lysates prepared with $0.2 \%$ SDS

Cell Viability Assay. L3.3 and PANC-1 cells were seeded in 96well plates and incubated overnight. To evaluate cell sensitivity to PEG-ADI treatment, medium was replaced with fresh medium in the presence or absence of $0.3 \mu \mathrm{g} / \mathrm{ml}$ PEG-ADI, and cell viability was monitored over 6 days. To assess the impact of miR-1291 on PEG-ADI treatment, cells were transfected with $5 \mathrm{nM}$ MSA or MSA/miR-1291 in the presence of $0.3 \mu \mathrm{g} / \mathrm{ml}$ PEG-ADI, and cell viability was monitored for 6 days, during which cell culture medium was replaced with fresh medium consisting of drug or RNA agents every 3 days. To determine the effects of miR-1291 on cisplatin efficacy, cells seeded in 96-well plates were treated with MSA or MSA/miR-1291 ( $1 \mathrm{nM}$ for AsPC- 1 cells and $5 \mathrm{nM}$ for PANC-1 cells) supplemented with $5 \mu \mathrm{M}$ cisplatin, and cell viability was monitored for 6 days using CellTiter-Glo assay kit (Promega).

Statistical Analysis. All values are mean \pm S.D., and data were analyzed by one- or two-way ANOVA (GraphPad Prism) depending upon the number of treatment groups and variables. Difference was considered as statistically significant when $P$ value was less than $0.05(P<0.05)$.

\section{Results}

Recombinant MSA/Mir-1291 Is Processed to Target miR-1291-5p in Human PC Cells. To investigate whether MSA/miR-1291 was processed to miR-1291-5p in all PC cells 
used in this study, selective RT-qPCR assays were conducted to quantify mature miR-1291-5p and pre-miR-1291 levels by using TaqMan stem-loop RT-qPCR assay kit and geneselective primers, respectively. Treatment with MSA/miR1291 led to one to two orders of magnitude increase in premiR-1291 in all three PC cell lines as compared with MSA or vehicle control treatments, indicating a successful transfection (Fig. 1A). Likewise, mature miR-1291-5p levels showed three orders of magnitude increase in cells treated with MSA/ miR-1291 compared with control MSA and vehicle treatments (Fig. 1B). Interestingly, miR-1291 level in AsPC-1 cells at 48 hours post-transfection was as high as that at 72 hours, whereas miR-1291 levels were decreasing in PANC-1 and L3.3 cells from 48 to 72 hours (Fig. 1B), indicating a longer half-life and potentially longer pharmacological effects for miR-1291 in AsPC-1 cells. These results demonstrated that high levels of mature miR-1291 were selectively released from MSA/miR-1291 in human PC cells, persisting for at least 72 hours.

MiR-1291 Reduces ASS1 Protein Expression and Arginine Levels Preferably in ASS1-Abundant PC Cells. Since our previous study identified ASS1 as an indirect target for miR-1291 (Tu et al., 2016), we investigated to what degree recombinant miR-1291 could alter ASS1 protein levels in PC cells. We first determined the basal levels of ASS1 protein in two PC cell lines: PANC-1 and L3.3. As shown in Fig. 2A, intrinsic ASS1 level in L3.3 cells is remarkably higher than that in PANC-1 cells. Thus, high ASS1-expressing L3.3 cell line was chosen to evaluate the impact of miR-1291. Our data showed that MSA/miR-1291 treatment led to approximately 25\% suppression of ASS1 protein levels in L3.3 cells at 48 and 72 hours as compared with MSA control treatment (Fig. 2B), supporting the actions of miR-1291 in the control of ASS1 expression.
We then determined the intracellular level of arginine by using a selective and accurate LC-MS/MS method. MSA/miR1291 treatment caused a $43 \%$ decrease [95\% confidence interval (CI): $28 \%-60 \%$ ] of arginine levels in L3.3 cells compared with MSA control treatment (Fig. 2C). By contrast, MSA/miR1291 did not have any statistically significant influence on arginine levels in PANC-1 cells (Fig. 2C) with low basal levels of ASS1 (Fig. 2A). Together, the results illustrated that miR1291 could modulate arginine synthesis via the regulation of ASS1 expression in ASS1-abundant PC cells.

MiR-1291 Sensitizes ASS1-Abundant PC Cells to Arginine Deprivation Therapy. Given the fact that effectiveness of arginine deprivation therapy is dependent upon ASS1 expression (Bowles et al., 2008), we further evaluated the influence of miR-1291 on the sensitivity of PC cells to PEGADI treatment. Indeed, PANC-1 cells with low or minimal ASS1 expression were sensitive to arginine depletion therapy, whereas L3.3 cells with high level of ASS1 expression were resistant to PEG-ADI (Fig. 3A). Interestingly, L3.3 cells became highly sensitive to PEG-ADI treatment (Fig. 3B) after the suppression of ASS1 by coadministered miR-1291 (Fig. 2B). In addition, compared with MSA control treatment, coadministration of MSA/miR-1291 led to a modest increase of PEG-ADI efficacy in the inhibition of PANC-1 cell viability, which was already responsive to PEG-ADI (Fig. 3B). These findings indicated that miR-1291 was effective at improving arginine depletion therapy against PC cells, which is attributed to the reduction of ASS1 protein levels.

MiR-1291 Modulates Glucose Uptake and Metabolism through Targeting GLUT1 in PC Cells. GLUT1, a main transporter of cellular glucose uptake, has been shown as a direct target of miR-1291 in renal cell carcinoma cells (Yamasaki et al., 2013). We thus assessed whether biologic miR-1291 could modulate GLUT1 protein expression in PC
A
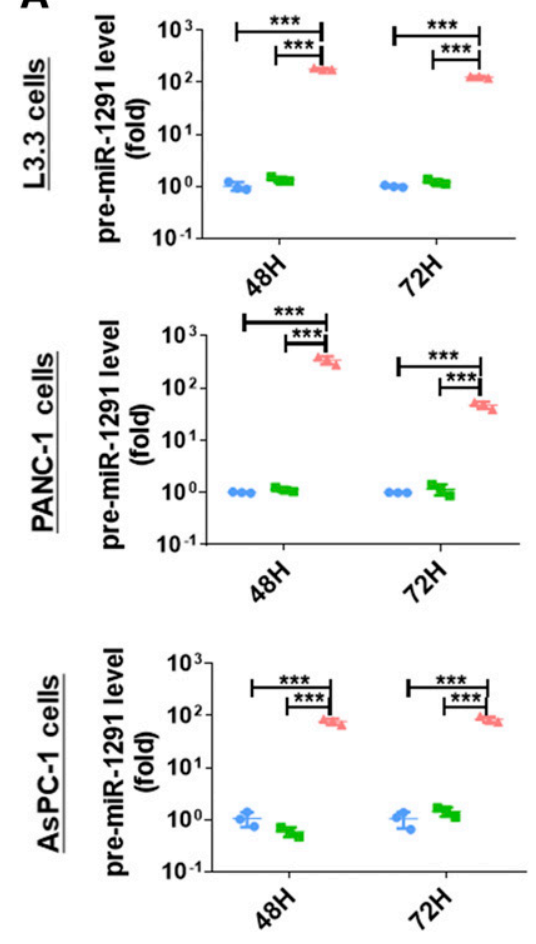

B
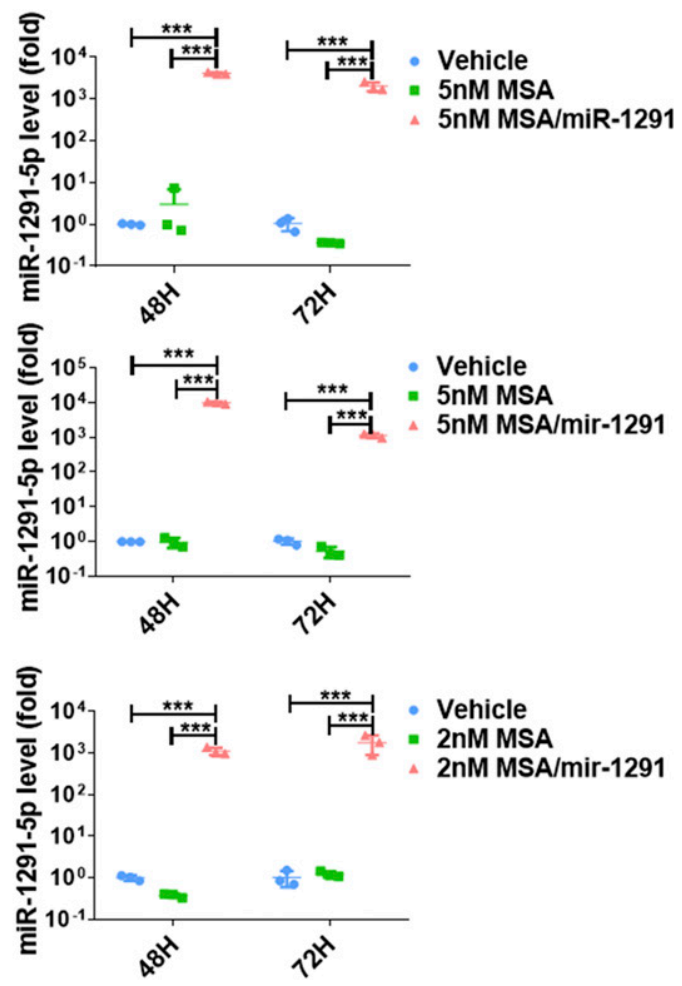

Fig. 1. Bioengineered MSA/miR-1291 is selectively processed to mature miR-1291$5 p$ in human PC cells. The levels of premiR-1291 (A) and mature miR-1291-5p (B) were remarkably higher in cells treated with MSA/miR-1291 than those treated with control MSA or vehicle. Values are mean \pm S.D. $\left(N=3\right.$ /group). ${ }^{* * *} P<0.001$, one-way ANOVA with Bonferroni posttests. 
A

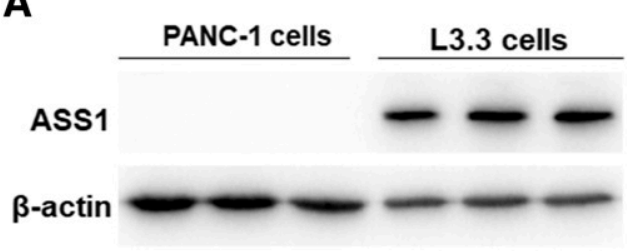

B

L3.3 cells

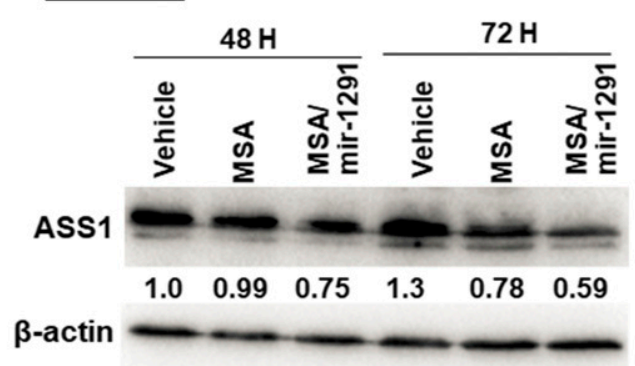

C
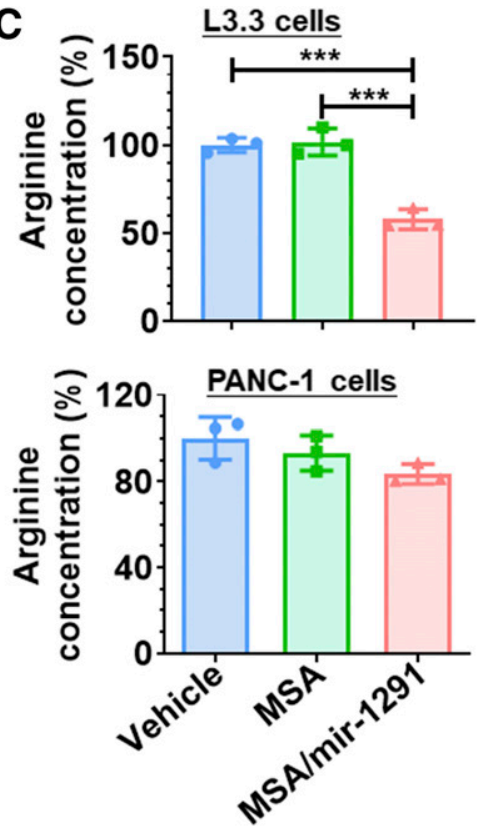

Fig. 2. MiR-1291 preferably reduces ASS1 protein expression and arginine levels in ASS1abundant PC cells. As revealed by Western blot analyses, ASS1 was highly expressed in L3.3 cells (A) and readily suppressed by bioengineered miR1291 (B). Cells were treated with vehicle, MSA, or MSA/miR-1291 (10 nM for L3.3 cells and $20 \mathrm{nM}$ for PANC-1 cells). Band density was determined by Image Laboratory software (Bio-Rad) and normalized to $\beta$-actin. The protein level in vehicle group was defined as 1.0. As a result, miR-1291 remarkably reduced intracellular arginine level in L3.3 cells, whereas it had minor impact in PANC-1 cells (C). Arginine concentrations were determined by selective LC-MS/MS method. Values are mean \pm S.D. $\left(N=3\right.$ per group). ${ }^{* * *} P<0.001$ (one-way ANOVA with Bonferroni post-tests) cells. Our results showed that MSA/miR-1291 treatment decreased GLUT1 protein levels in AsPC-1 cells by $34 \%$ and $66 \%$ at 48 and 72 hours, respectively, compared with MSA control (Fig. 4A). By contrast, a relatively modest effect of MSA/miR-1291 on GLUT1 protein expression was observed in PANC-1 cells-around $5 \%$ and $23 \%$ reduction at 48 and 72 hours, respectively-as compared with MSA control treatment.

We further investigated the consequent impact on cellular glucose uptake capacity by using 2-NBDG-based glucose uptake assay. The results showed that glucose uptake rates were inhibited by MSA/miR-1291 for about $52 \%$ and $48 \%$ in AsPC-1 (95\% CI: 2\%-120\%) and PANC-1 (95\% CI: 12\%-72\%) cells, respectively, as compared with MSA control treatments
(Fig. 4B), indicating the importance of miR-1291-GLUT1 signaling in the control of glucose uptake in PC cells.

To delineate the impact of downregulating GLUT1 on glucose metabolism in PC cells, culture media and cell lysates from both cell lines were collected at 48 hours post-treatment and subjected to LC-MS/MS analysis of glucose and two major metabolites of glycolysis, pyruvate, and lactate. Although pyruvate concentration was lower than lower limit of quantification, glucose and lactate were readily quantified. Our data (Fig. 4C) showed that intracellular levels of glucose and lactate in AsPC-1 cells were reduced by miR-1291 for around 62\% (95\% CI: $38 \%-121 \%$ ) and 100\% (95\% CI: $74 \%-157 \%$ ), respectively. This was associated with $35 \%$ higher levels of extracellular glucose levels (95\% CI: $-48 \%$ to $-19 \%$ ) and

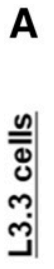
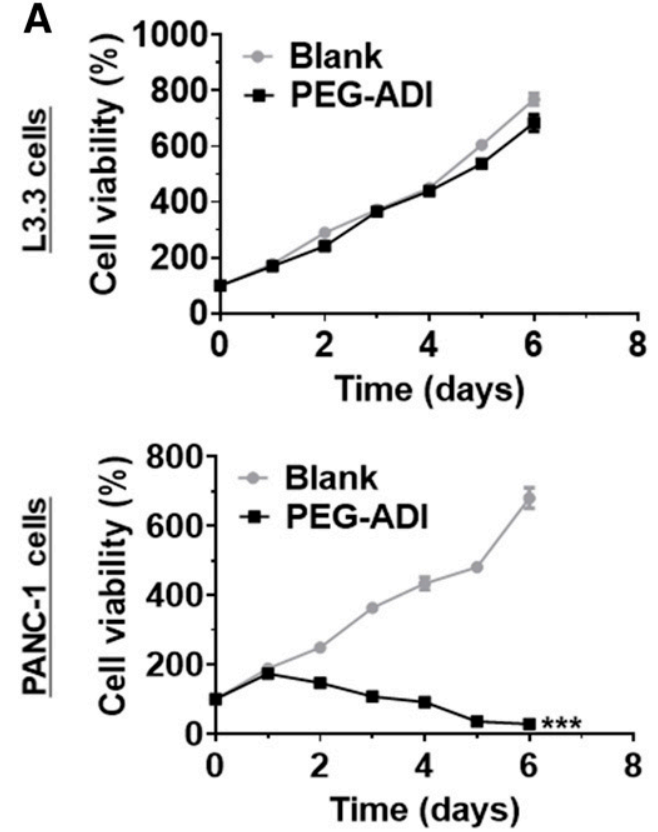

B
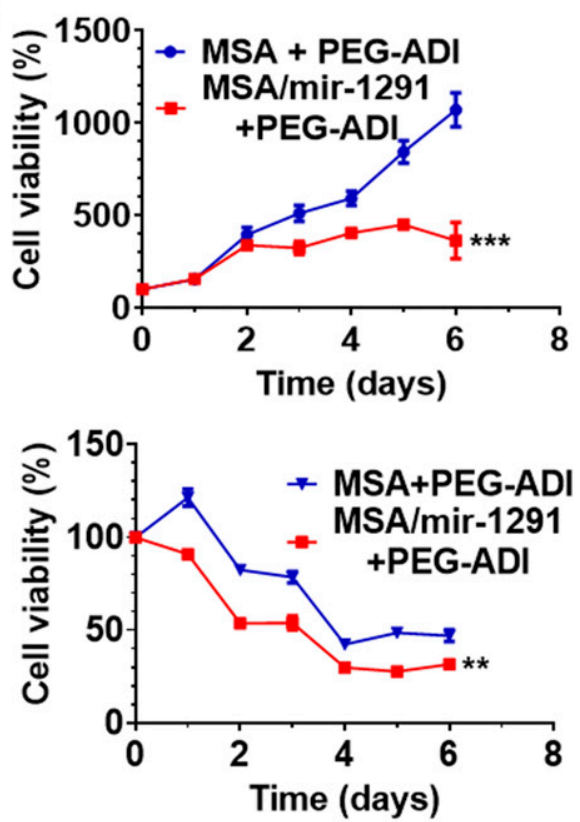

Fig. 3. Bioengineered miR-1291 sensitizes PC cells to PEG-ADI therapy. (A) L3.3 cells were resistant to PEG-ADI treatment because of high ASS1 expression, whereas PANC-1 cells with low ASS1 expression were sensitive to PDGADI $(0.3 \mu \mathrm{g} / \mathrm{ml})$. (B) Coadministration of miR-1291 sharply sensitized L3.3 cells to PEG-ADI therapy and slightly improved PDG-ADI efficacy in PANC-1 cells. Cell viability was determined by using a CellTiter-Glo kit, and the value on day 0 was defined as $100 \%$. Values are mean \pm S.D. ( $N=4$ per group). ${ }^{* *} P<0.01 ;{ }^{* * *} P<$ 0.001 , compared with corresponding control treatment (two-way ANOVA with Bonferroni post-tests). 


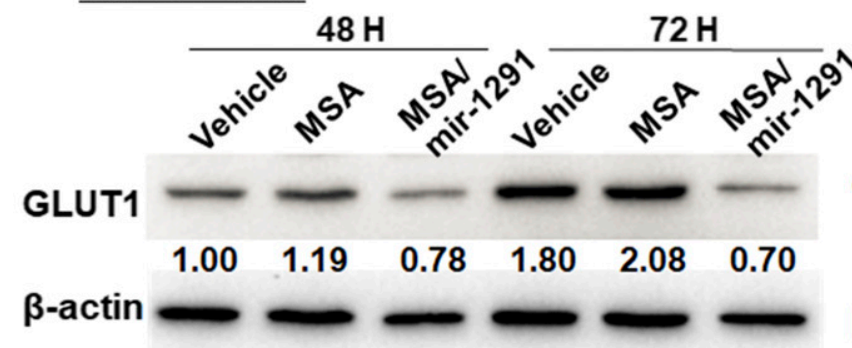

PANC-1 cells

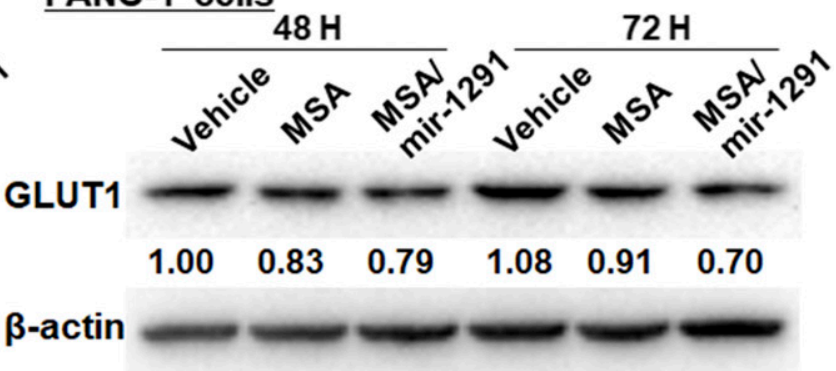

B
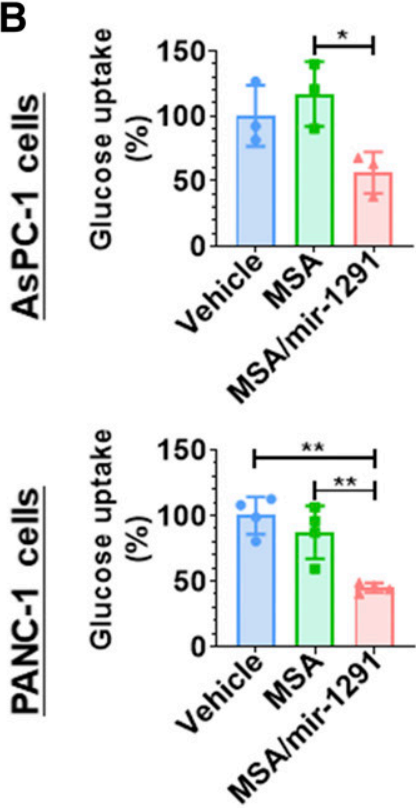

C
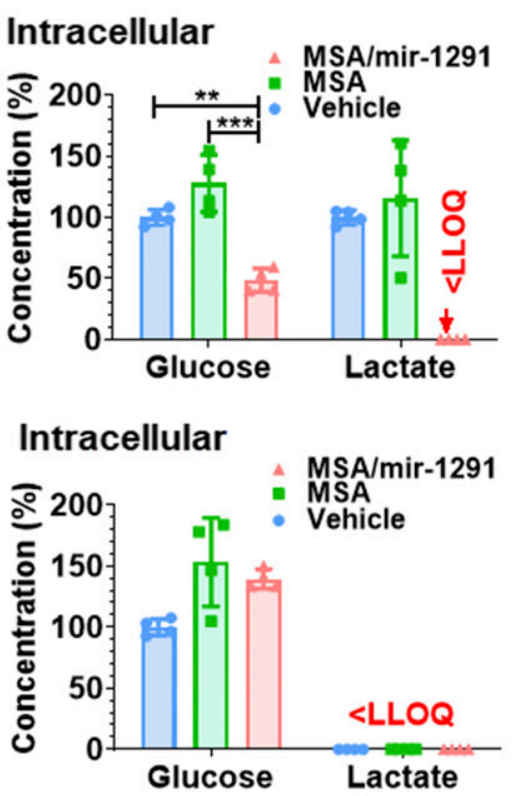
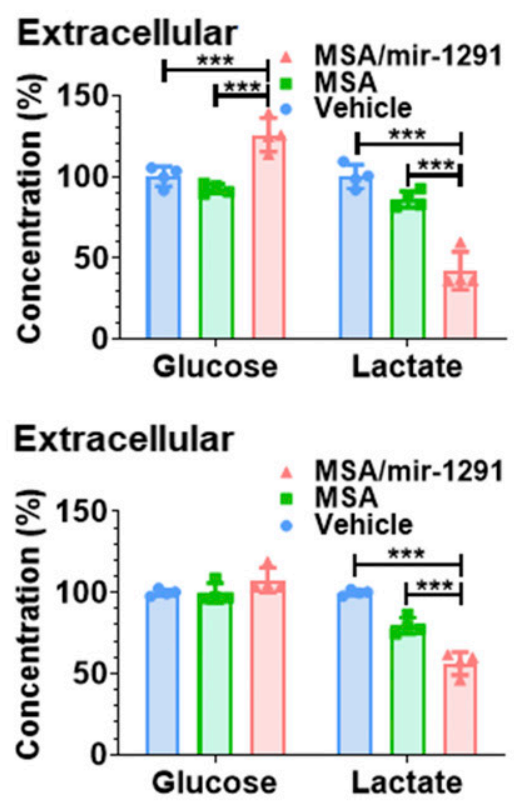

Fig. 4. MiR-1291 modulates GLUT1 protein expression to control glucose uptake and metabolism in human PC cells. (A) Treatment with biologic miR1291 decreased the protein levels of GLUT1 in AsPC-1 and PANC-1 cells. Cells were treated with vehicle, MSA, or MSA/miR-1291 (5 nM for AsPC-1 cells and $20 \mathrm{nM}$ for PANC-1 cells), and GLUT1 protein was examined by immunoblot analyses. Band density was determined by Image Laboratory software (Bio-Rad), and normalized to respective $\beta$-actin level. The protein levels in vehicle group at 48 hours were defined as 1.0. (B) Glucose uptake capacity was suppressed by miR-1291 in AsPC-1 and PANC-1 cells, as determined by the 2-NBDG-based glucose uptake assay. (C) Subsequently, the intracellular and extracellular levels of intrinsic glucose and lactate were altered in AsPC-1 and PANC-1 cells at 48 hours post-treatment, as determined by LC-MS/MS method. Values are mean \pm S.D. $(N=4$ /group). $* P<0.05 ; * * P<0.01 ; * * * P<0.001$, compared with MSA or vehicle control (one- or two-way ANOVA with Bonferroni post-tests). LLOQ, lower limit of quantification.

$51 \%$ lower extracellular lactate levels (95\% CI: 29\%-59\%, compared with MSA) in miR-1291-treated AsPC-1 cells, indicating the influence of miR-1291-GLUT1 signaling on cellular glucose uptake and, consequently, intracellular glucose metabolism. Nevertheless, miR-1291 did not alter intracellular glucose homeostasis but had minor impact on extracellular lactate concentrations (95\% CI: 13\%-33\%) in PANC-1 cells, suggesting the presence of compensatory pathways. Together, these results demonstrated that miR-1291 may reduce glucose uptake and metabolism through the modulation of GLUT1.

MiR-1291 Inhibits Glycolytic Capacity of PC Cells and Greatly Improves Cell Sensitivity to Cisplatin. The Seahorse XF Glycolytic Rate Assay was then conducted to measure the real-time proton efflux rate (PER) of live cells. Proton efflux from live cells consists of both mitochondrialproduced $\mathrm{CO}_{2^{-}}$and glycolytic-produced lactate-derived acidification, and ROT/AA inhibits mitochondrial function and thus enables the calculation of glycolytic PER (Fig. 5). The results showed that miR-1291-treated PC cells had a slightly lower basal glycolysis than control cells (Fig. 5B).
Furthermore, treatment with biologic miR-1291 led to around $50 \%$ decrease of compensatory glycolysis in both AsPC-1 (95\% CI: $33 \%-67 \%)$ and PANC-1 (95\% CI: 1\%-18\%) cells as compared with control RNA or vehicle treatments (Fig. 5C). This real-time live cell glycolysis study revealed an important role of miR-1291 in the control of glycolytic capacity of PC cells.

Lastly, we determined to what degree miR-1291 may alter the sensitivities of AsPC-1 and PANC-1 cells to chemo-drug cisplatin since inhibition of GLUT1-mediated glycolysis was able to enhance the anticancer efficacy of cisplatin (Loar et al., 2010; Li et al., 2017). Our data showed that, compared with control treatments, coadministration of bioengineered miR1291 distinctly increased PC cell sensitivities to cisplatin (Fig. 6), supporting the influence of miR-1291-mediated inhibition of glycolysis on cisplatin efficacy.

\section{Discussion}

With the understanding of vital roles of genome-derived noncoding RNAs in disease initiation and progression, there is ever growing interest in developing miRNA-based therapies. 

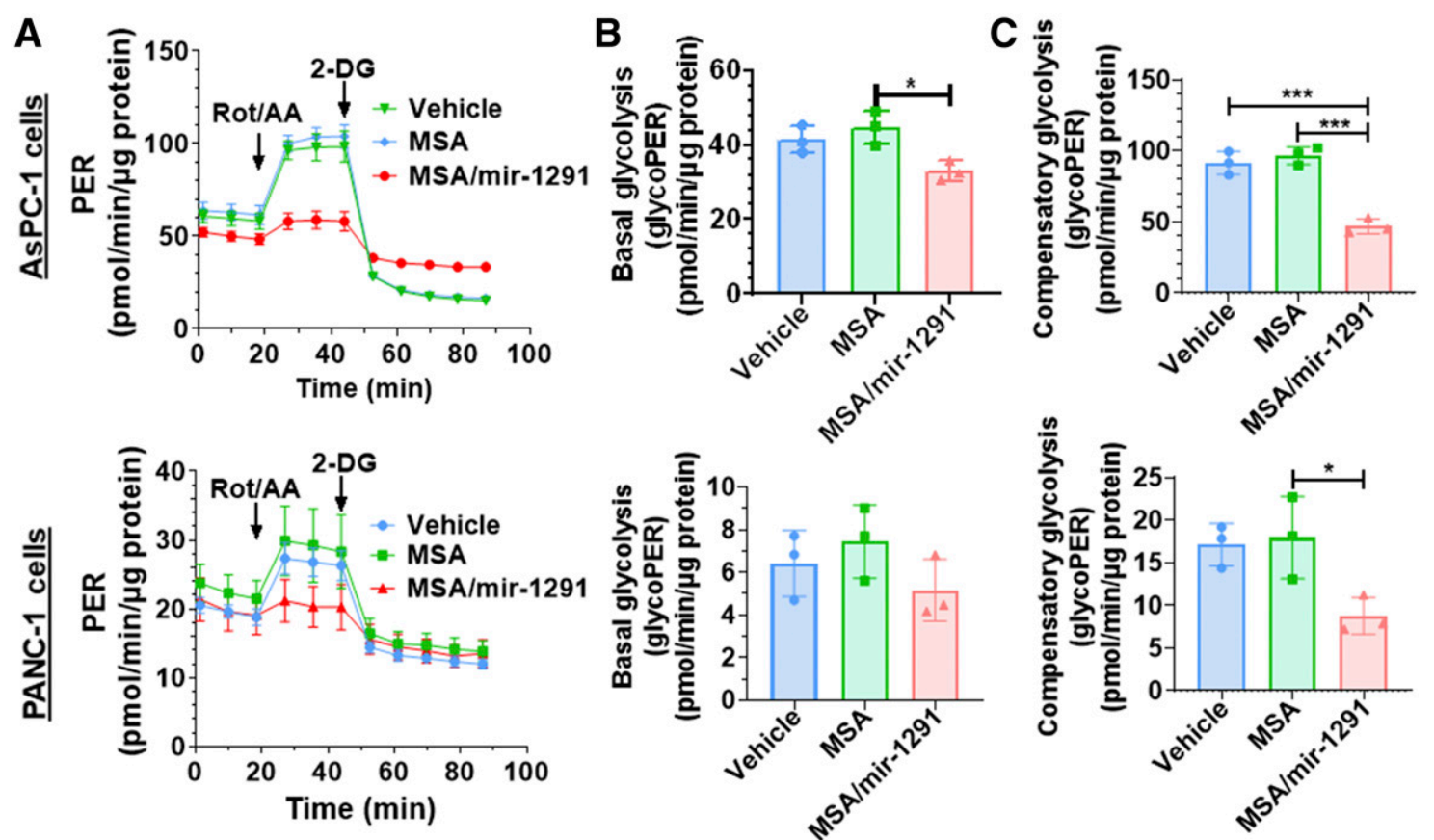

Fig. 5. MiR-1291 controls the glycolytic rate of PC cells. Cells were treated with MSA/miR-1291 (5 nM for AsPC-1 cells and $20 \mathrm{nM}$ for PANC-1 cells) or control MSA and vehicle for 48 hours. Real-time ECARs, OCRs at basal level and after the addition of ROT/AA, and 2-deoxy-D-glucose (2-DG) were monitored by the Seahorse XF Glycolytic Rate Assay and converted to the PERs (A). (B) MiR-1291 obviously decreased the basal glycolytic capacity in AsPC-1 cells, whereas it had minimal impact in PANC-1 cells. (C) The compensatory glycolytic capacity in both AsPC-1 and PANC-1 cells was reduced by miR-1291 to approximately 50\%. Values are mean \pm S.D. ( $N=3$ /group). $* P<0.05 ; * * * P<0.001$ (one-way ANOVA with Bonferroni post-tests). glycoPER, glycolytic PER.

Our recent efforts have led to the establishment of a novel platform to produce recombinant or bioengineered miRNA molecules for miRNA replacement therapy (Wang et al., 2015; Jilek et al., 2019; Tu et al., 2019). Different from chemoengineered RNA agents made in vitro and comprised of extensive and various types of artificial modifications, bioengineered RNA agents are produced and folded in live cells and thus may better recapitulate the structures, biologic functions, and safety profiles of natural RNAs (Yu et al., 2019, 2020). By using bioengineered miR-1291 agents, the present study established the role of tumor-suppressive miR-1291 in the perturbation of PC cell metabolism. In particular, miR1291 modulates the expression of ASS1 and GLUT1, crucial arginine synthesis enzyme and glucose uptake transporter, respectively, to control intracellular arginine levels, glucose uptake, and glycolytic capacity. As a result, coadministration of miR-1291 is effective to improve the sensitivity of PC cells to PEG-ADI and cisplatin.

The oncolytic actions of miR-1291 via the regulation of various cancer-related targets have been consistently demonstrated by several groups. Researchers have shown that miR-1291 inhibits esophageal squamous cell carcinoma cell proliferation and invasion through direct targeting of mucin 1 (Luo et al., 2015) and prostate cancer cell proliferation and tumorigenesis by regulating the mediator of RNA polymerase II transcription subunit 1 (Cai et al., 2019). We have revealed that miR-1291 suppresses multiple (proto-)oncogenes to control PC cell proliferation and tumorigenesis (Bi et al., 2014; Tu et al., 2016; Chen et al., 2020). Meanwhile, miR1291 is able to sensitize PC cells to doxorubicin therapy via the suppression of multidrug resistance-associated protein 1 (Pan et al., 2013; Li et al., 2015). Consistent with previous studies on miR-1291 in the regulation of ASS1 and GLUT1 using miR1291-expressing plasmids and synthetic miR-1291 mimics (Yamasaki et al., 2013; Tu et al., 2016), the present study demonstrated reintroduction of miR-1291 into PC cells using novel biologic miR-1291 agents effectively reduces ASS1 protein levels. Although there is an absence of miR-1291 response element within the 3 '-untranslated region of ASS1, miR-1291 is able to regulate a number of transcription factors, such as Forkhead Box A2, E2F transcription factor 1, and estrogenrelated receptor $\alpha$ (Agarwal et al., 2015; Tu et al., 2019; Chen
AsPC-1 cells

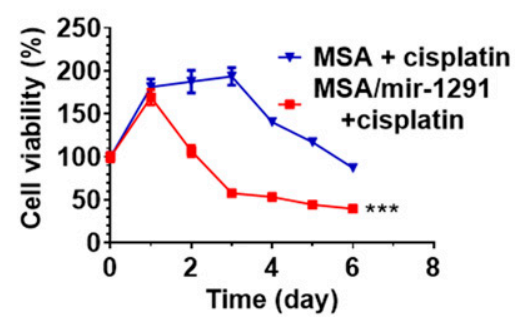

PANC-1 cells

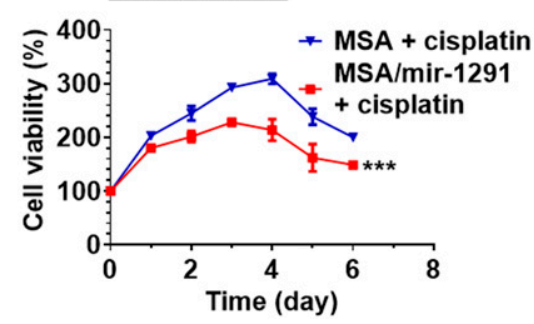

Fig. 6. Coadministration of bioengineered miR-1291 increases the sensitivity of PC cells to chemo-drug cisplatin. Cells were treated with MSA/miR-1291 or control MSA ( $1 \mathrm{nM}$ for AsPC-1 cells and $5 \mathrm{nM}$ for PANC-1 cells) in the presence of $5 \mu \mathrm{M}$ cisplatin for 6 days. Cell viability was determined by using a CellTiter-Glo kit, and viability value on day 0 was defined as $100 \%$. Values are mean \pm S.D. $\left(N=3\right.$ /group). ${ }^{* * *} P<0.001$, compared with control treatment (two-way ANOVA with Bonferroni post-tests). 
et al., 2020) that might modulate ASS1 gene expression (Pandey et al., 2020), which awaits further investigation. Furthermore, it is unknown whether miR-1291 is able to regulate the expression of other enzymes involved in glucose metabolism. Anyhow, these findings suggest an important role of miR-1291 in PC cell aminolyses and glycolysis.

Deprivation of arginine is one way to interfere with cancer metabolism toward the management of tumor progression (Delage et al., 2010). PEG-ADI was designed to deplete the extracellular arginine by converting extracellular arginine back to citrulline (Patil et al., 2016). The effectiveness of PEGADI has been established in multiple types of cancers, including PC, advanced hepatocellular carcinoma, and pleural mesothelioma, as manifested by the decrease of plasma arginine levels (Yang et al., 2010; Ott et al., 2013; Lowery et al., 2017; Abou-Alfa et al., 2018), which is dependent on the status of ASS1. Our previous study has shown that tissues from patients with PC are usually deficient with ASS1, whereas there are still some patients and PC cell lines showing high level of ASS1 protein (Bowles et al., 2008). Consistent with previous finding on a positive correlation between PEG-ADI efficacy and ASS1 deficiency in PC cells (Bowles et al., 2008), this study found that L3.3 cells with high level of ASS1 protein was resistant to PEG-ADI treatment, whereas PANC-1 cells showing low level of ASS1 were modestly sensitive to PEG-ADI. Excitingly, reduction of ASS1 expression by miR-1291 sharply sensitized L3.3 cells to PEG-ADI and enhanced the efficacy of PEG-ADI in PANC-1 cells. Our findings support ASS1 as a viable target to improve precision arginine deprivation therapy, and the effectiveness of coadministration of ASS1 modulator with PEG-ADI is amenable to critical in vivo studies.

Targeting cancer biomarker GLUT1 or other factors underlying glucose uptake/metabolism is another strategy to develop pharmacological agent for cancer therapy (Ooi and Gomperts, 2015; Counihan et al., 2018; Wuest et al., 2018). For example, GLUT1 inhibitor WZB117 (2-Fluoro-6-(m-hydroxybenzoyloxy) Phenyl m-Hydroxybenzoate) was shown to effectively inhibit lung cancer cell proliferation in vitro and xenograft tumor growth in vivo (Liu et al., 2012). The glucose analog 2-deoxyglucose, a GLUT1 substrate that competitively inhibits glucose metabolism, has entered into clinical investigations for the treatment of several types of cancer (Maschek et al., 2004; Dwarakanath et al., 2009), and ${ }^{18}$ F-fluordeoxyglucose for theranostics is actively under evaluation (Kahle et al., 2020). Consistent with previous study on renal cell carcinoma (Yamasaki et al., 2013), the present study demonstrated the actions of miR-1291 in the control of GLUT1 in PC cells. Most importantly, our studies established the important impact of miR-1291-GLUT1 signaling on cellular glucose uptake, and consequently, glucose metabolism and glycolytic capacity. Compared with more remarkable effects shown in AsPC-1 cells, the influence of miR-1291 on glucose levels and glycolysis was much lower or absent in PANC-1 cells. Indeed, the latter was associated with a lower degree of decrease in GLUT1 protein levels. Nevertheless, one cannot rule out possible presence of multiple or compensatory mechanisms for cellular glucose uptake and subsequent metabolism in heterogenous carcinoma cells, which warrants further investigations.

Cisplatin, an effective broad-spectrum chemotherapeutic drug, exerts antitumor effect mainly through the inhibition of DNA replication (Jamieson and Lippard, 1999). However, the development of chemoresistance caused by complex mechanisms (Galluzzi et al., 2012) may result in therapeutic failure and thus demand for more effective combination treatment or alternative therapy. Several reports suggest that inhibition of GLUT1 or glycolysis sensitizes cancer cells to cisplatin, including esophageal, ovarian, and bladder cancers (Loar et al., 2010; Li et al., 2017; Sawayama et al., 2019). One possible mechanism is that oxidative stress is required or able to enhance cisplatin-induced DNA damage and cell death, and inhibition of glycolysis may lead to higher levels of reactive oxygen species and lower levels of antioxidants (e.g., lactate) (Sattler and Mueller-Klieser, 2009; Galluzzi et al., 2012). The present study on miR-1291-GLUT1 pathway supports the concept that interference of glycolysis, as manifested by the lower intracellular glucose and lactate levels, as well as decrease in glycolytic capacity are effective means to improve cisplatin efficacy, which warrant further investigations with more complex in vivo models.

In conclusion, by using novel bioengineered miR-1291 agent, our studies have demonstrated a role of miR-1291 in the regulation of $\mathrm{PC}$ cell metabolism. The suppression of ASS1, preferably in ASS1-abundant L3.3 cells by miR-1291, causes the reduction of intracellular arginine levels and thus sensitizes the cells to arginine deprivation therapy. Meanwhile, miR-1291 modulates GLUT1 protein expression to control glucose uptake and glycolysis capacity of PC cells, leading to an enhancement of cisplatin efficacy. These findings may offer new insights into an improved understanding of molecular mechanisms behind the oncolytic actions of miR1291 and the development of more effective and precision therapies.

\section{Authorship Contributions}

Participated in research design: Tu, Duan, Bold, Gonzalez, Kim, Yu.

Conducted experiments: Tu, Duan, Liu, Zhang.

Contributed to new reagents or analytical tools: Tu, Kim, Liu, Yu. Performed data analysis: Tu, Kim, Yu.

Wrote or contributed to the writing of the manuscript: $\mathrm{Tu}, \mathrm{Kim}, \mathrm{Yu}$.

\section{References}

Abou-Alfa GK, Qin S, Ryoo BY, Lu SN, Yen CJ, Feng YH, Lim HY, Izzo F, Colombo M, Sarker D, et al. (2018) Phase III randomized study of second line ADI-PEG 20 plus best supportive care versus placebo plus best supportive care in patients with advanced hepatocellular carcinoma. Ann Oncol 29:1402-1408.

Agarwal V, Bell GW, Nam JW, and Bartel DP (2015) Predicting effective microRNA target sites in mammalian mRNAs. eLife 4:e05005.

Asgari Y, Zabihinpour Z, Salehzadeh-Yazdi A, Schreiber F, and Masoudi-Nejad A (2015) Alterations in cancer cell metabolism: the Warburg effect and metabolic adaptation. Genomics 105:275-281.

Bi H-C, Pan Y-Z, Qiu J-X, Krausz KW, Li F, Johnson CH, Jiang C-T, Gonzalez FJ, and $\mathrm{Yu}$ A-M (2014) N-methylnicotinamide and nicotinamide N-methyltransferase are associated with microRNA-1291-altered pancreatic carcinoma cell metabolome and suppressed tumorigenesis. Carcinogenesis 35:2264-2272.

Bowles TL, Kim R, Galante J, Parsons CM, Virudachalam S, Kung HJ, and Bold RJ (2008) Pancreatic cancer cell lines deficient in argininosuccinate synthetase are sensitive to arginine deprivation by arginine deiminase. Int $J$ Cancer 123 : $1950-1955$

Cai Q, Zhao A, Ren L, Chen J, Liao K, Wang Z, and Zhang W (2019) MicroRNA-1291 mediates cell proliferation and tumorigenesis by downregulating MED1 in prostate cancer. Oncol Lett 17:3253-3260.

Chen QX, Wang WP, Zeng S, Urayama S, and Yu AM (2015) A general approach to high-yield biosynthesis of chimeric RNAs bearing various types of functional small RNAs for broad applications. Nucleic Acids Res 43:3857-3869.

Chen Y, Zhou Y, Han F, Zhao Y, Tu M, Wang Y, Huang C, Fan S, Chen P, Yao X, et al (2020) A novel miR-1291-ERR $\alpha$-CPT1C axis modulates tumor cell proliferation, metabolism and tumorigenesis. Theranostics 10:7193-7210.

Counihan JL, Grossman EA, and Nomura DK (2018) Cancer metabolism: current understanding and therapies. Chem Rev 118:6893-6923.

Dai S, Peng Y, Zhu Y, Xu D, Zhu F, Xu W, Chen Q, Zhu X, Liu T, Hou C, et al. (2020) Glycolysis promotes the progression of pancreatic cancer and reduces cancer cell sensitivity to gemcitabine. Biomed Pharmacother 121:109521. 
Daylami R, Muilenburg DJ, Virudachalam S, and Bold RJ (2014) Pegylated arginine deiminase synergistically increases the cytotoxicity of gemcitabine in human pancreatic cancer. J Exp Clin Cancer Res 33:102.

DeBerardinis RJ and Chandel NS (2016) Fundamentals of cancer metabolism. Sci Adv 2:e1600200.

Delage B, Fennell DA, Nicholson L, McNeish I, Lemoine NR, Crook T, and Szlosarek PW (2010) Arginine deprivation and aroininosuccinate synthetase expression in the treatment of cancer. Int J Cancer 126:2762-2772.

Dwarakanath BS, Singh D, Banerji AK, Sarin R, Venkataramana NK, Jalali R, Vishwanath PN, Mohanti BK, Tripathi RP, Kalia VK, et al. (2009) Clinical studie for improving radiotherapy with 2-deoxy-D-glucose: present status and future prospects. J Cancer Res Ther 5 (Suppl 1):S21-S26.

Galluzzi L, Senovilla L, Vitale I, Michels J, Martins I, Kepp O, Castedo M, and Kroemer G (2012) Molecular mechanisms of cisplatin resistance. Oncogene $\mathbf{3 1}$ $1869-1883$

Gebert LFR and MacRae IJ (2019) Regulation of microRNA function in animals. Nat Rev Mol Cell Biol 20:21-37.

$\mathrm{Ha} \mathrm{M}$ and Kim VN (2014) Regulation of microRNA biogenesis. Nat Rev Mol Cell Biol 15:509-524.

Ho P, Duan Z, Batra N, Jilek JL, Tu M-J, Qiu J-X, Hu Z, Wun T, Lara PN, DeVere White RW, et al. (2018) Bioengineered noncoding RNAs selectively change cellular miRNome profiles for cancer therapy. J Pharmacol Exp Ther 365:494-506.

Hsu PP and Sabatini DM (2008) Cancer cell metabolism: warburg and beyond. Cell 134:703-707.

Jamieson ER and Lippard SJ (1999) Structure, recognition, and processing of cisplatin-DNA adducts. Chem Rev 99:2467-2498.

Jilek JL, Zhang QY, Tu MJ, Ho PY, Duan Z, Qiu JX, and Yu AM (2019) Bioengineered let-7c inhibits orthotopic hepatocellular carcinoma and improves overall survival with minimal immunogenicity. Mol Ther Nucleic Acids 14: 498-508.

Kahle XU, Montes de Jesus FM, Glaudemans AWJM, Lub-de Hooge MN, JorritsmaSmit A, Plattel WJ, van Meerten T, Diepstra A, van den Berg A, Kwee TC, et al (2020) Molecular imaging in lymphoma beyond ${ }^{18}$ F-FDG-PET: understanding the biology and its implications for diagnostics and therapy. Lancet Haematol 7 : e479-e489.

Kawauchi K, Araki K, Tobiume K, and Tanaka N (2008) p53 regulates glucose metabolism through an IKK-NF-kappaB pathway and inhibits cell transformation. Nat Cell Biol 10:611-618.

Li MM, Addepalli B, Tu MJ, Chen QX, Wang WP, Limbach PA, LaSalle JM, Zeng S, Huang M, and Yu AM (2015) Chimeric microRNA-1291 biosynthesized efficiently in Escherichia coli is effective to reduce target gene expression in human carcinoma cells and improve chemosensitivity. Drug Metab Dispos 43:1129-1136.

Li P, Yang X, Cheng Y, Zhang X, Yang C, Deng X, Li P, Tao J, Yang H, Wei J, et al. (2017) MicroRNA-218 increases the sensitivity of bladder cancer to cisplatin by targeting Glut1. Cell Physiol Biochem 41:921-932.

Liu Y, Cao Y, Zhang W, Bergmeier S, Qian Y, Akbar H, Colvin R, Ding J, Tong L, Wu $\mathrm{S}$, et al. (2012) A small-molecule inhibitor of glucose transporter 1 downregulates glycolysis, induces cell-cycle arrest, and inhibits cancer cell growth in vitro and in vivo. Mol Cancer Ther 11:1672-1682.

Liu Z, Tu M-J, Zhang C, Jilek JL, Zhang Q-Y, and Yu A-M (2019) A reliable LC-MS/ MS method for the quantification of natural amino acids in mouse plasma: method validation and application to a study on amino acid dynamics during hepatocellular carcinoma progression. J Chromatogr B Analyt Technol Biomed Life Sci 1124 $72-81$.

Loar P, Wahl H, Kshirsagar M, Gossner G, Griffith K, and Liu JR (2010) Inhibition of glycolysis enhances cisplatin-induced apoptosis in ovarian cancer cells. Am J Obstet Gynecol 202:371.e1-371.e8.

Lowery MA, Yu KH, Kelsen DP, Harding JJ, Bomalaski JS, Glassman DC, Covington CM, Brenner R, Hollywood E, Barba A, et al. (2017) A phase 1/1B trial of ADI-PEG 20 plus nab-paclitaxel and gemcitabine in patients with advanced pancreatic adenocarcinoma. Cancer 123:4556-4565.

Luo H, Guo W, Wang F, You Y, Wang J, Chen X, Wang J, Wang Y, Du Y, Chen X, et al. (2015) miR-1291 targets mucin 1 inhibiting cell proliferation and invasion to promote cell apoptosis in esophageal squamous cell carcinoma. Oncol Rep 34: 2665-2673.

Martinez-Outschoorn UE, Peiris-Pagés M, Pestell RG, Sotgia F, and Lisanti MP (2017) Cancer metabolism: a therapeutic perspective. Nat Rev Clin Oncol 14: $11-31$.

Maschek G, Savaraj N, Priebe W, Braunschweiger P, Hamilton K, Tidmarsh GF, De Young LR, and Lampidis TJ (2004) 2-deoxy-D-glucose increases the efficacy of adriamycin and paclitaxel in human osteosarcoma and non-small cell lung cancers in vivo. Cancer Res 64:31-34.

Nalls D, Tang S-N, Rodova M, Srivastava RK, and Shankar S (2011) Targeting epigenetic regulation of miR-34a for treatment of pancreatic cancer by inhibition of pancreatic cancer stem cells. PLoS One 6:e24099.
Ooi AT and Gomperts BN (2015) Molecular pathways: targeting cellular energy metabolism in cancer via inhibition of SLC2A1 and LDHA. Clin Cancer Res 21: $2440-2444$

Ott PA, Carvajal RD, Pandit-Taskar N, Jungbluth AA, Hoffman EW, Wu B-W, Bomalaski JS, Venhaus R, Pan L, Old LJ, et al. (2013) Phase I/II study of pegylated arginine deiminase (ADI-PEG 20) in patients with advanced melanoma. Invest New Drugs 31:425-434.

Pan Y-Z, Zhou A, Hu Z, and Yu A-M (2013) Small nucleolar RNA-derived microRNA hsa-miR-1291 modulates cellular drug disposition through direct targeting of ABC transporter ABCC1. Drug Metab Dispos 41:1744-1751.

Pandey N, Lanke V, and Vinod PK (2020) Network-based metabolic characterization of renal cell carcinoma. Sci Rep 10:5955.

Patil MD, Bhaumik J, Babykutty S, Banerjee UC, and Fukumura D (2016) Arginine dependence of tumor cells: targeting a chink in cancer's armor. Oncogene $\mathbf{3 5}$ : 4957-4972.

Pavlova NN and Thompson CB (2016) The emerging hallmarks of cancer metabolism. Cell Metab 23:27-47.

Sattler UG and Mueller-Klieser W (2009) The anti-oxidant capacity of tumour glycolysis. Int $J$ Radiat Biol 85:963-971.

Sawayama H, Ogata Y, Ishimoto T, Mima K, Hiyoshi Y, Iwatsuki M, Baba Y, Miyamoto Y, Yoshida N, and Baba H (2019) Glucose transporter 1 regulates the proliferation and cisplatin sensitivity of esophageal cancer. Cancer Sci 110: 1705-1714.

Siegel RL, Miller KD, and Jemal A (2020) Cancer statistics, 2020. CA Cancer J Clin 70:7-30.

Tu M-J, Ho PY, Zhang Q-Y, Jian C, Qiu J-X, Kim EJ, Bold RJ, Gonzalez FJ, Bi H, and Yu A-M (2019) Bioengineered miRNA-1291 prodrug therapy in pancreatic cancer cells and patient-derived xenograft mouse models. Cancer Lett 442:82-90.

Tu M-J, Pan Y-Z, Qiu J-X, Kim EJ, and Yu A-M (2016) MicroRNA-1291 targets the FOXA2-AGR2 pathway to suppress pancreatic cancer cell proliferation and tumorigenesis. Oncotarget 7:45547-45561.

Wang WP, Ho PY, Chen QX, Addepalli B, Limbach PA, Li MM, Wu WJ, Jilek JL, Qiu JX, Zhang HJ, et al. (2015) Bioengineering novel chimeric microRNA-34a for prodrug cancer therapy: high-yield expression and purification, and structural and functional characterization. J Pharmacol Exp Ther 354:131-141.

Wu D-H, Liang H, Lu S-N, Wang H, Su Z-L, Zhang L, Ma J-Q, Guo M, Tai S, and Yu S (2018) miR-124 suppresses pancreatic ductal adenocarcinoma growth by regulating monocarboxylate transporter 1-mediated cancer lactate metabolism. Cell Physiol Biochem 50:924-935.

Wu G (2013) Functional Amino Acids in Nutrition and Health, Springer, New York. Wuest M, Hamann I, Bouvet V, Glubrecht D, Marshall A, Trayner B, Soueidan O-M Krys D, Wagner M, Cheeseman C, et al. (2018) Molecular imaging of GLUT1 and GLUT5 in breast cancer: a multitracer positron emission tomography imaging study in mice. Mol Pharmacol 93:79-89.

Xi Y, Yuan P, Li T, Zhang M, Liu M-F, and Li BJ (2020) hENT1 reverses chemoresistance by regulating glycolysis in pancreatic cancer. Cancer Lett 479:112-122.

Yamamoto N, Ueda-Wakagi M, Sato T, Kawasaki K, Sawada K, Kawabata K, Akagawa M, and Ashida H (2011) Measurement of glucose uptake in cultured cells. Curr Protoc Pharmacol 71:12.14.1-12.14.26.

Yamasaki T, Seki N, Yoshino H, Itesako T, Yamada Y, Tatarano S, Hidaka H, Yonezawa T, Nakagawa M, and Enokida H (2013) Tumor-suppressive microRNA1291 directly regulates glucose transporter 1 in renal cell carcinoma. Cancer Sci 104:1411-1419.

Yang TS, Lu SN, Chao Y, Sheen IS, Lin CC, Wang TE, Chen SC, Wang JH, Liao LY, Thomson JA, et al. (2010) A randomised phase II study of pegylated arginine deiminase (ADI-PEG 20) in Asian advanced hepatocellular carcinoma patients. $\mathrm{Br}$ J Cancer 103:954-960.

Yi W, Tu M-J, Liu Z, Zhang C, Batra N, Yu A-X, and Yu A-M (2020) Bioengineered miR328-3p modulates GLUT1-mediated glucose uptake and metabolism to exert synergistic antiproliferative effects with chemotherapeutics. Acta Pharm Sin B 10:159-170.

Yu AM, Batra N, Tu MJ, and Sweeney C (2020) Novel approaches for efficient in vivo fermentation production of noncoding RNAs. Appl Microbiol Biotechnol 104: 1927-1937.

Yu AM, Jian C, Yu AH, and Tu MJ (2019) RNA therapy: are we using the right molecules? Pharmacol Ther 196:91-104.

Address correspondence to: Dr. Edward J. Kim, Division of Hematology and Oncology, Department of Internal Medicine, University of California (UC) Davis School of Medicine, 4501 X Street, Suite 3016, Oak Park Research Bldg., Sacramento, CA 95817. E-mail: jhkim@ucdavis.edu; or Dr. Ai-Ming $\mathrm{Yu}$, Department of Biochemistry and Molecular Medicine, UC Davis School of Medicine, 2700 Stockton Blvd. Suite 2130, Oak Park Research Bldg., Sacramento, CA 95817. E-mail: aimyu@ucdavis.edu 